\title{
Adsorption and Diffusion Characteristics of 2-Naphthol from Aqueous Media by Chitosan-ENR Biocomposites
}

\author{
R. GUNASUNDERI ${ }^{1,2^{*}}$, AND M. R. H. MAS HARIS ${ }^{1}$
}

\begin{abstract}
Chitosan entrapped ENR-50 (CTS-t-ENR) biocomposites developed were studied for the absorption and desorption of 2-naphthol in aqueous media. Biocomposites comprising chitosan (CTS) immobilized or trapped in a partially crosslinked ENR (designated as CTS-t-ENR) was prepared by homogenising CTS in ENR-50 latex with curative agents in the presence of acetic acid. It was found that absorption increased with the increase in the initial 2-naphthol concentrations. Chitosan powder was found to be a poor absorbent compared CTS-t-ENR biocomposites. Desorption study revealed that the 2-naphthol diffused slowly in water. The biocomposites exhibited a good slowrelease properties and this was proven by the kinetic study using zero order, first order, Higuchi equation and Kosmeyer Peppas equation. Thus, these biocomposites with a good controlled release and swelling properties could be very useful in agricultural application.
\end{abstract}

Key words: Chitosan; epoxidized natural rubber; slow-release matrices; pasticides

One of the convenient and cheap methods of controlling pests and weeds is by using pesticide which is widely used in the agricultural field. Pesticides are known to create lots of problems in the environment through leaching, runoff, and volatilisation. This issue can be overcome by using a slow release pesticide as slow-release pesticide has been established as vital keys to various environmental problems caused by the obsolete pesticides. With slow-release pesticide, the required amount is lowered, the efficiency of pesticide usage is improved, and environmental pollution problems are practically negligible.

One of the main issues in producing or developing slow release pesticide is the utilization of an appropriate biodegradable material for the matrix. Polymer-coated conventional slow-release pesticides have been widely developed lately (Gerstl \& Mingelgrin 1998; Sopeña et al. 2009) with chitosan being one of the polymers (Li et al. 2012). Chitosan is a linear polysaccharides of a $(1 \rightarrow 4)$-linked 2-amino-2-deoxy-p-D-glucopyranose obtained from $\mathrm{N}$-deacetylation of chitin which is commonly found in crustacean (Chandra \& Rustgi 1998). CTS is known to increase the usage of marine waste due to its non-hazardous biodegradable properties (Dutta et al. 2004). Incorporation of chitosan in a rubber matrix may further extend its capability on variable release behaviour of insecticide due to the double advantages of both entrapments of the polymer and sorption by chitosan. There have been numerous reports on CTS and epoxidized

\footnotetext{
${ }^{1}$ School of Distance Education, Universiti Sains Malaysia, 11800 Minden, Penang

${ }^{2}$ School of Chemical Sciences, Universiti Sains Malaysia, 11800 Minden, Pulau Pinang

* Corresponding author (e-mail: rgunasunderi@usm.my)
} 
natural rubber (ENR-50) biocomposites (Letwattanaseri et al. 2009; Ismail et al. 2011; Riyajan \& Sukhlaaied 2013; Raju et al. 2013; Mas \& Raju 2014) but till date no reports have been reported on chitosan-rubber composite on its use as the carrier in slow release of pesticides.

In this backdrop, we report the development of chitosan entrapped in epoxidized natural rubber for the slow release for 2-naphthol (pesticide precursors). The purpose of entrapment of chitosan in ENR-50 was to improvise the absorption and the desorption capacity of 2-naphthol and to stimulate the biodegradation property of ENR-50 to further sustained release. Therefore attempts were made to absorb the 2-Naphthol physically in the composites and to study the release of it as a slow-release matrix in the agricultural field.

\section{MATERIALS AND METHODS}

\section{Materials}

ENR-50 latex with $\mathrm{Mw}$ of $3.8 \times 10^{5} \mathrm{Da}$ was supplied by Malaysian Rubber Board, Kuala Lumpur, Malaysia. The actual epoxy content was determined using Bruker Avance-400 NMR spectrometer to be $51.05 \%$. Chitosan (CTS) with Mw of 105,100 Da and degree deacetylation of about $95 \%$ was provided by Advanced Materials Research Centre, Kedah, Malaysia. The other compounding ingredients used were zinc oxide, stearic acid, $\mathrm{N}$-cyclohexyl-2-benzothiazole sulphonamide (CBS), zinc oxide, stearic acid, and sulphur, were all purchased from Bayer Ltd (Malaysia) and used as received. 2-naphthol was purchased from BDH Chemical Ltd England.

\section{Processing of Composite with Different Chitosan Loading}

A partially crosslinked ENR was prepared by compounding the ingredients as shown in Table 1 (0 phr CTS) using a high-speed homogenizer in a beaker at ambient temperature $\left(27-30^{\circ} \mathrm{C}\right)$ for $5 \mathrm{~min}$. Then the compounded rubber was cast in a glass mould and set to air dry at ambient temperature for $24 \mathrm{~h}$ before placing in an oven at $60^{\circ} \mathrm{C}$ for an additional $24 \mathrm{~h}$. The resulting material obtained was a partially crosslinked ENR and was designated herein as $0 \mathrm{phr}$ CTSt-ENR (the letter ' $t$ ' refers the term 'trapped'). CTS $(5.0 \mathrm{~g})$ was added to $100 \mathrm{ml}$ of $2 \% \mathrm{v} / \mathrm{v}$ acetic acid to form the slurry. Then known quantity $(2.5,5,10$, and $15 \mathrm{phr})$ of this slurry was added to ENR 50 latex and mixed using a high speed homogenizer at ambient temperature $\left(27-30^{\circ} \mathrm{C}\right)$ for $2 \mathrm{~min}$. Subsequently, the remaining compounding ingredients (Table 1) were added with continuous mixing for another 3 min. The compounded materials were cast in a glass mould and set to air dry at ambient temperature for $24 \mathrm{~h}$ before placing in an oven at $60^{\circ} \mathrm{C}$ for an additional $24 \mathrm{~h}$.

Table 1. Formulation of ENR 50-t-CTS biocomposites.

\begin{tabular}{c|c}
\hline Compounding Ingredients & Dry weight $(\mathrm{phr})^{\mathrm{a}}$ \\
\hline ENR-50 & 100 \\
Chitosan $^{\mathrm{b}}$ & $0,2.5,5,10$ and 15 \\
$50 \%$ zinc oxide & 1.8 \\
$50 \%$ sulphur & 1.5 \\
$50 \%$ zinc diethyl \\
dithiocarbamate \\
$50 \%$ antioxidant
\end{tabular}


Method for 2-Naphthol AbsorptionDesorption Study

Absorption experiment. A stock solution of 2-naphthol was prepared by dissolving 700 $\mathrm{mg}$ of the compound in $1000 \mathrm{ml}$ of distilled water inside a 1 litre volumetric flask. Then standard solutions containing 300, 400, 500 and $600 \mathrm{mg} / 1$ of 2-naphthol were prepared from the stock solution. $0.2 \mathrm{~g}$ of each type of biocomposites (prepared from ENR-50 and with different loadings of chitosan: $0,2.5,5,10$, and $15 \mathrm{phr}$ ) was placed in separate bottles, and 10 $\mathrm{ml}$ of a standard solution was added to each bottle. This procedure was repeated for each standard solution. Then the bottles were covered with paraffin film and kept sanding at ambient temperature $\left(25-30^{\circ} \mathrm{C}\right)$ for $48 \mathrm{~h}$. Subsequently, the resulting biocomposites were isolated using filter paper and placed in an oven set at $40^{\circ} \mathrm{C}$ to dry for $24 \mathrm{~h}$ i.e. until a constant weight was obtained for each sample.

The solution was analysed using an UV spectrometer. The UV absorbance was measured using an UV/Vis spectrophotometer in $1 \mathrm{~cm}$ quartz cells. The absorption spectrum of each sample was determined in the UV region (200-400 nm) by using a Perkin-Elmer Lambda 35 UV/VIS spectrophotometer. The standard solution of the 2-naphthol used was found to exhibit a wavelength at $326 \mathrm{~nm}$. The height of the peak at this wavelength was used throughout for calculating the 2-naphthol concentration. The amount of 2-naphthol disappearing from solution was assumed to be absorbed by sample whereas the amount of 2-naphthol appearing in the solution was the amount of left behind. All absorption experiments were performed for three times, and average values were used for all calculations. The absorption after $48 \mathrm{~h}$ was calculated using Equation 1 and 2:
$\%$ of absorption $=\frac{(C o-C i)}{C i} \times 100 \%$

Where, $C o$ is the initial concentration $(\mathrm{mg} / \mathrm{l})$ and $\mathrm{Ci}$ is the final concentration $(\mathrm{mg} / \mathrm{l})$.

$\%$ of absorption capacity $=\frac{(\mathrm{Co}-\mathrm{Ci}) \mathrm{V}}{W} \times 100 \%$

Where, Co is the initial concentration $(\mathrm{mg} / \mathrm{l})$ and $C i$ is the final concentration $(\mathrm{mg} / \mathrm{l})$, $V$ the volume (1) of the solution, and $W$ is the weight $(\mathrm{g})$ of the adsorbent used.

Desorption experiment. To investigate desorption of 2-naphthol from the biocomposites following method was carried out. After the absorption took place, the biocomposites were dried and kept. These dried biocomposites $(0$, $2.5,5,10$, and $15 \mathrm{phr}$ ) were then placed in a beaker containing $50 \mathrm{ml}$ of distilled water and covered with paraffin film for $48 \mathrm{~h}$. Samples were withdrawn after $24 \mathrm{~h}$, and the solution is circulated through a column for three times before analysis. The samples were then placed again in the same solution. After $48 \mathrm{~h}$ samples were withdrawn and the solution is circulated again through a column three times before analysis. The removed samples were put in fresh $50 \mathrm{ml}$ distilled water and the solution was analysed after $48 \mathrm{~h}$. Samples were placed in clean distilled water every $48 \mathrm{~h}$. This procedure was repeated until the 2-naphthol was no longer detected. All desorption experiments were performed for three times, and average values were used for all calculations. The 2-naphthol concentration were analysed using the UV spectrometer. The standard solution of the 2-naphthol used was found to exhibit a wavelength at $326 \mathrm{~nm}$. The height of the peak at this wavelength was used throughout for calculating the 2-naphthol concentration. 
Amount of 2-naphthol release was calculated using Equation 3:

$$
\% \text { amount release }=\frac{\begin{array}{c}
\text { The amount of } \\
\text { 2-naphtholreleased } \\
\text { to the solution }
\end{array}}{\begin{array}{c}
\text { The initial amount } \\
\text { of 2-naphthol absorbed }
\end{array}} \times 100
$$

\section{RESULTS AND DISCUSSION}

\section{Effect of Chitosan Loading on the Adsorption of 2-Naphtol}

The effect of chitosan loading on 2-naphthol (700 ppm) absorption by CTS-t-ENR biocomposites was investigated, and the results are presented in Figures 1 and 2. It was found that chitosan powder had the lowest absorption and the absorption capacity compared to 0 phr biocomposites. Therefore it could be said that chitosan was not a good adsorbent for 2-naphthols since chitosan is known to have different capacities to sorb organic compounds. As seen from Figures 1 and 2, generally the amounts of absorption were not considerably affected by chitosan loading. There was only a slight increase in the 2-naphthol absorption with the entrapment of chitosan in the rubber. These were noticeable from the figure and table that at $2.5 \mathrm{phr}$ the absorption and the absorption capacity increased compared to the rubber by itself and increase in the chitosan loading beyond that did not show a significant increase. At a low concentration of 2-naphthol their absorption amount remained almost the same for all biocomposites. Chitosan powder is non-porous and the chitosan entrapped in the rubber matrix showed and increased in pore volume (Figure 2) suggesting that there was more intra-particle surface than the pores in the rubber matrix itself. Hence, entrapment of chitosan increased the overall absorption capacity. This suggested that after a particular loading of chitosan, the maximum absorption was achieved and therefore the number of molecules bound to the adsorbent and the number of free molecules remaind constant even with further chitosan loading.

\section{Effect of 2-Naphthol Concentration on the Adsorption of 2-Naphtol}

Result in Figures 1 and 2 shows that the uptake increased with the increase in the initial 2-naphthol concentrations. It was evident that the absorption was influenced by the initial concentration. It is well-known that with the increase of the concentration, the adsorbed amount increased as long as the binding sites are not saturated. Besides that initial concentration of the 2-naphthol was a significant driving force to overcome the mass transfer resistance of 2-naphthol between the aqueous and solid phase. An increase in the initial concentration enhanced the interaction between the 2-naphthol and the surface of the samples. The enhancement in the absorption process is also related to the increase in the number of collisions between the 2-naphthol molecules and the biocomposites (Hameed \& Hakimi 2008). If an absorption process for 2-naphthol uptake was a physical process, the uptake was usually reversible and reliant on the equilibrium between the 2-naphthol concentration in the solution and the 2-naphthol content on the surface of the composite. Hence the process of absorption was also not favourable at low concentration. Increase in 2-naphthol concentration accelerated the diffusion of 2-naphthol molecules from solution to the adsorbent surface due to the increase in driving force of the concentration gradient. 


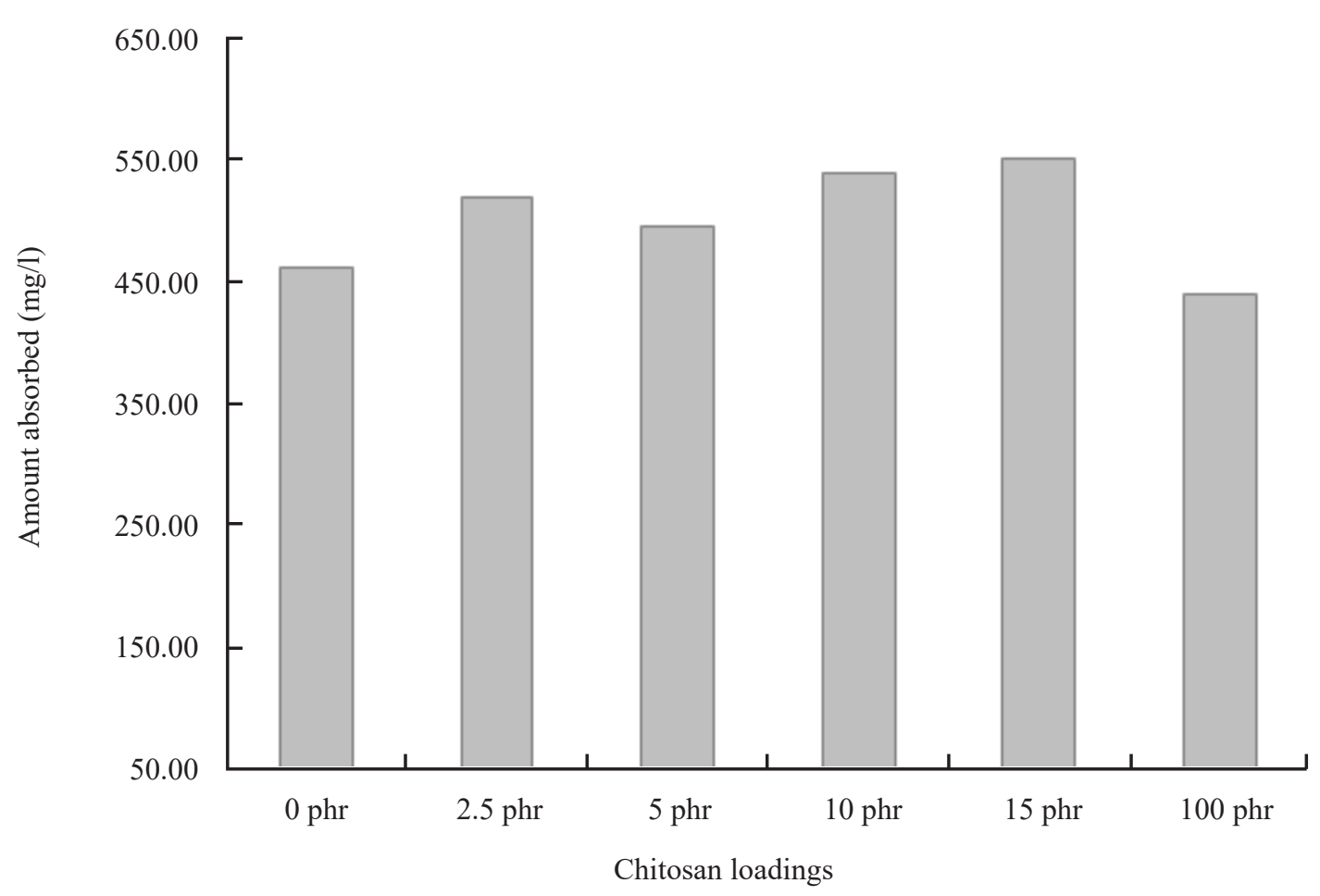

Figure 1. Effect of chitosan loading on the adsorption of 2-Naphtol.

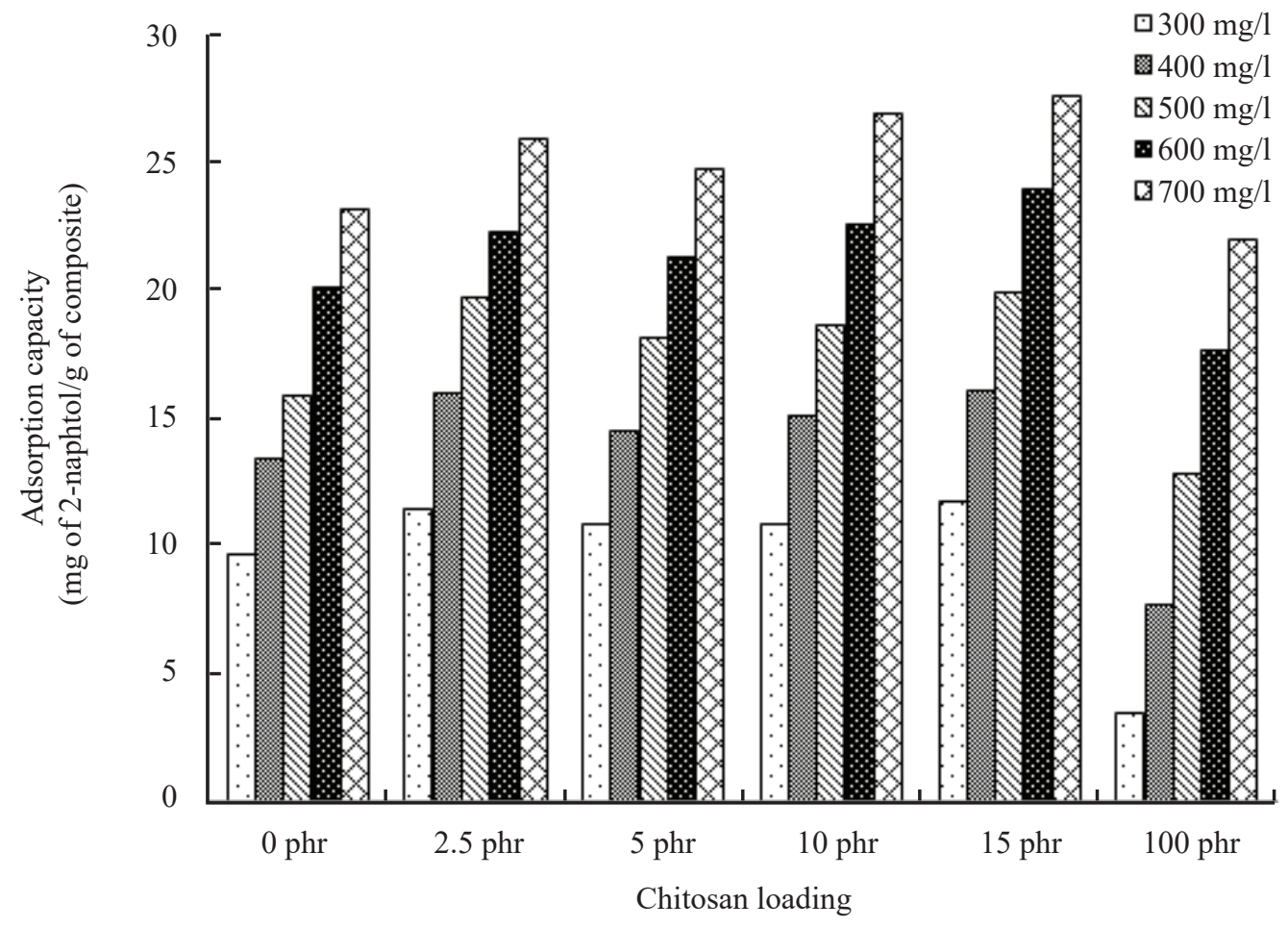

Figure 2. Effect of chitosan loading on the adsorption capacity of 2-Naphtol. 
Figure 3 depicts the theoretical value versus the experimental value of 2-naphthol absorption of the CTS-t-ENR biocomposites. These values were calculated using Equation 4 shown below. Based on these data it was very obvious that chitosan contributes to these unpredicted effects to the biocomposites at higher loading (10 and $15 \mathrm{phr}$ ). The effect was mainly due to the voids created by CTS shrinkage during the drying process. These voids allowed the CTS to swell to the maximum to fill up the void by absorbing the water which had penetrated through the rubber matrices. However, at low loading, the contribution of chitosan was negligible as the amount of the chitosan presented could be too little. Based on the data presented in it was noticeable that the absorption was not purely dependent on the amount of chitosan loading but also other factors such as solubility. This explained that absorption of any substance was also related to the solubility effect of that substance.

$\underset{\text { Cbiocomposites }}{\text { Theoretical value, }}=\frac{a A 1-b A 2)}{c} \times 100$

where, $A_{1}=\%$ of 2-naphthol absorbed by CTS $A_{2}=\%$ of 2-naphthol absorbed by 0phrCTS-t-ENR

$a=$ weight in $\mathrm{g}$ of rubber in the biocomposites

$b=$ weight in $\mathrm{g}$ of CTS in the biocomposites $c=$ weight in $\mathrm{g}$ of the biocomposites.

\section{Effect of Chitosan Loading on the 2-naphthol Desorption}

2-naphthol released from chitosan-ENR-50 composites is shown in Figure 4 respectively. It was obvious from the plots (Figure 4) that the 2-naphthol release increased with chitosan loading. Since chitosan powder adsorption was not good therefore desorption studies were not carried out on it. Desorption studies were conducted with a sample which had highest 2-naphthol adsorption.
The release of 2-naphthol entrapped in the biocomposites could only occur when the water penetrates the network to swell up the biocomposites and forming of wetting pores and followed by dissolution of the 2-naphthol and allowed it to diffuse through the wetting pores and the polymer matrix along the aqueous path to the surface. Finally, the 2-naphthol would diffuse to the bulk solution through the solid/liquid interface. Thus the release of the 2-naphthol was correlated to the swelling nature of the biocomposites which was important in the slow release studies. Overall the release of 2-naphthol followed two-phase processes which was the initial burst release followed by slow and sustained release. The rapid initial desorption of 2-naphthol as a surface phenomenon. Besides that, the initial release could also be related to the swelling of the biocomposites which assist the dynamic activity of the 2-naphthol within the biocomposites. 2-naphthol had poor solubility $(0.74 \mathrm{~g} / 1 \mathrm{in}$ water) and high hydrophobicity $\left(\log \mathrm{K}_{\mathrm{ow}}\right.$ in the range of $2.01-2.84)$. The octanol-water partition coefficient $\left(\mathrm{K}_{\mathrm{ow}}\right)$ is a measure of the equilibrium concentration of a compound between octanol and water that indicates the potential for partitioning into soil organic matter (i.e., a high $\mathrm{K}_{\mathrm{ow}}$ indicates a compound which will preferentially partition into soil organic matter rather than water). $\mathrm{K}_{\text {ow }}$ is inversely related to the solubility of a compound in water (Karickhoff et al. 1979). Determined the diffusion of the 2 naphthol and the transfer from solid/liquid interface. The concentration gradient. Therefore low concentration gradients was formed due to the poor solubility of 2-naphthol resulting in slower diffusion and mass transfer. When a pesticide has a high hydrophobicity characteristic, it tends to have a good affinity/interaction with the chitosan which would also result in a slower diffusion 


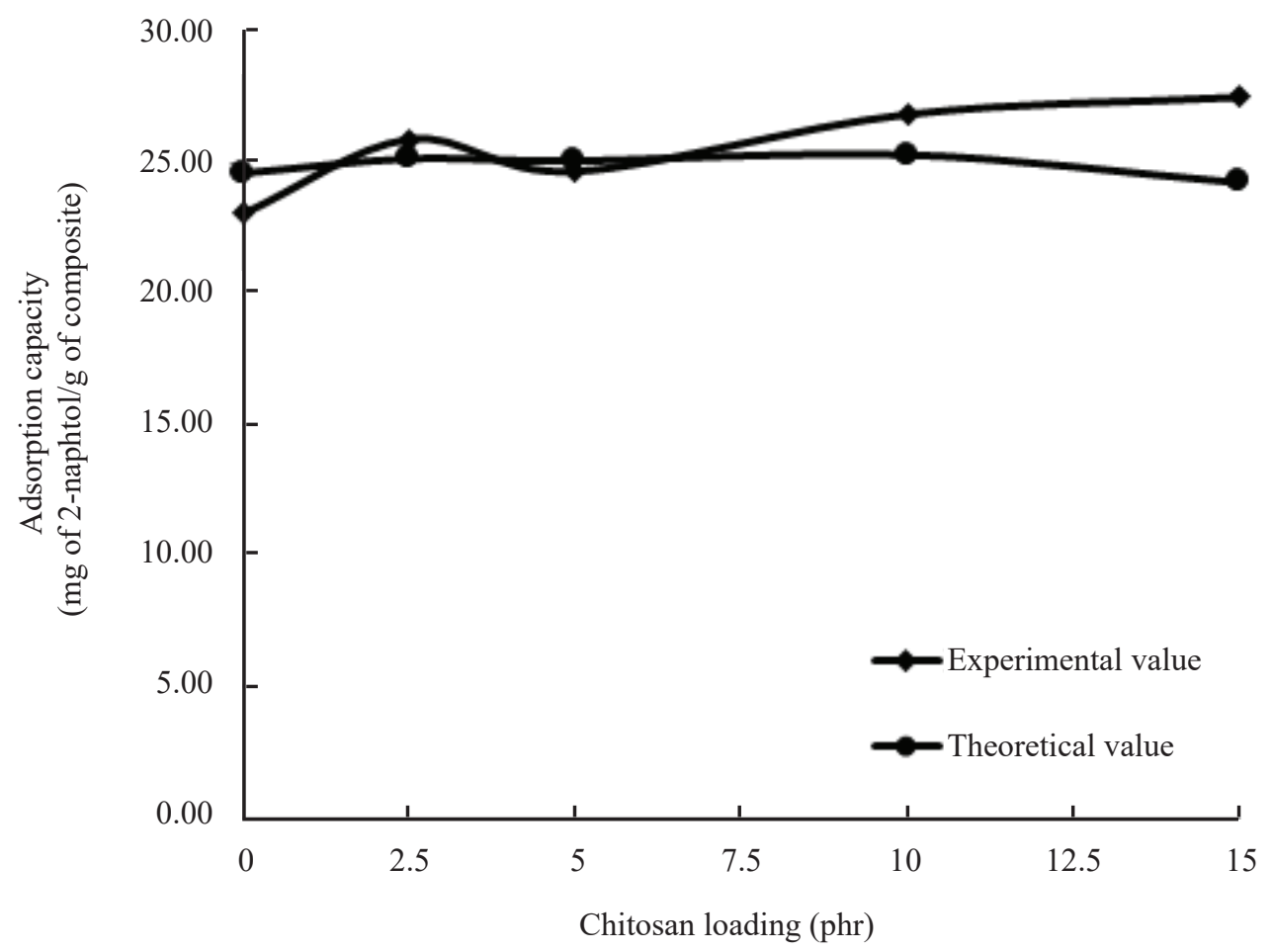

Figure 3. Experimental value versus theoretical value of copper absorption by CTS-t-ENR biocomposites.

rate. Since 2-naphthol is highly hydrophobicity and poor in solubility both these nature will contribute to a slow release of 2-naphthol from the CTS-t-ENR biocomposites (Gerstl et al. 1998).

Data presented in Figure 5 indicates that the burst release (Teixeira et al. 1990) is also related to the chitosan loading in the rubber matrix. The higher the chitosan loading the release is also higher. This is probably due to the nature of chitosan which swells easily in waters. Thus, it allows the composite to swell and allows the 2-naphthol molecules to diffuse through the free volumes and porous to the surface. Based on Figure 5 it was found that after $72 \mathrm{~h}$ the amount of release drops indicated that the amount of 2-naphthol in the release media had saturated and prevented further release. Therefore there was a need to replace or release medium every $72 \mathrm{~h}$ to prevent saturation and reabsorption from taking place. Once the release medium had been replaced the amount of release for the first $24 \mathrm{~h}$ increased. This situation was carried out to mimic a reallife situation in agriculture field. Whereby, the amount of 2-naphthol release would be dependent on the water content in the soil.

In order to postulate the kinetics and the mechanism of the 2-naphthol release from the biocomposites, the diffusion data obtained was fitter using kinetic equations such as zeroorder rate (Lobo et al. 2012), first-order rate (Costa \& Sousa 2001), Higuchi square root of time (Costa \& Sousa 2001) and Ritger-Peppas (Wang et al. 2009). The diffusion data fitted well with zero-order rate equation. It was evident 


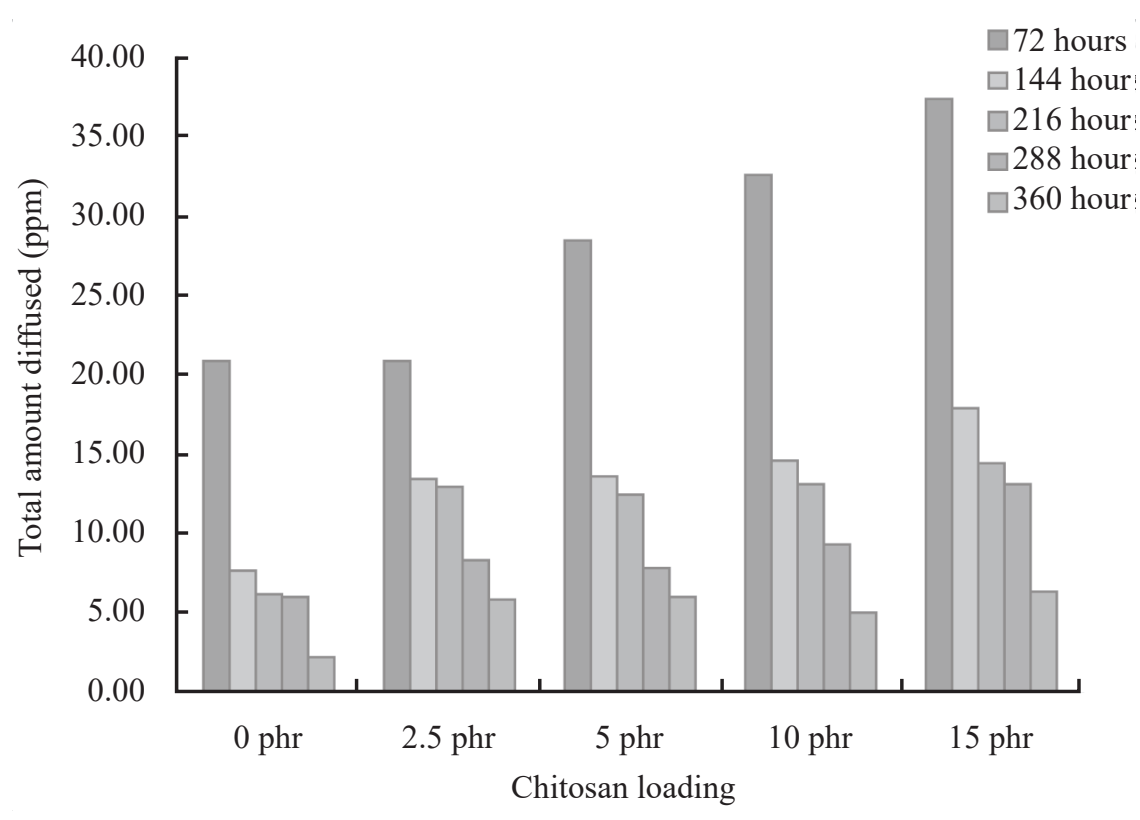

Figure 4. Effect of chitosan loading on the 2-naphthol desorption.

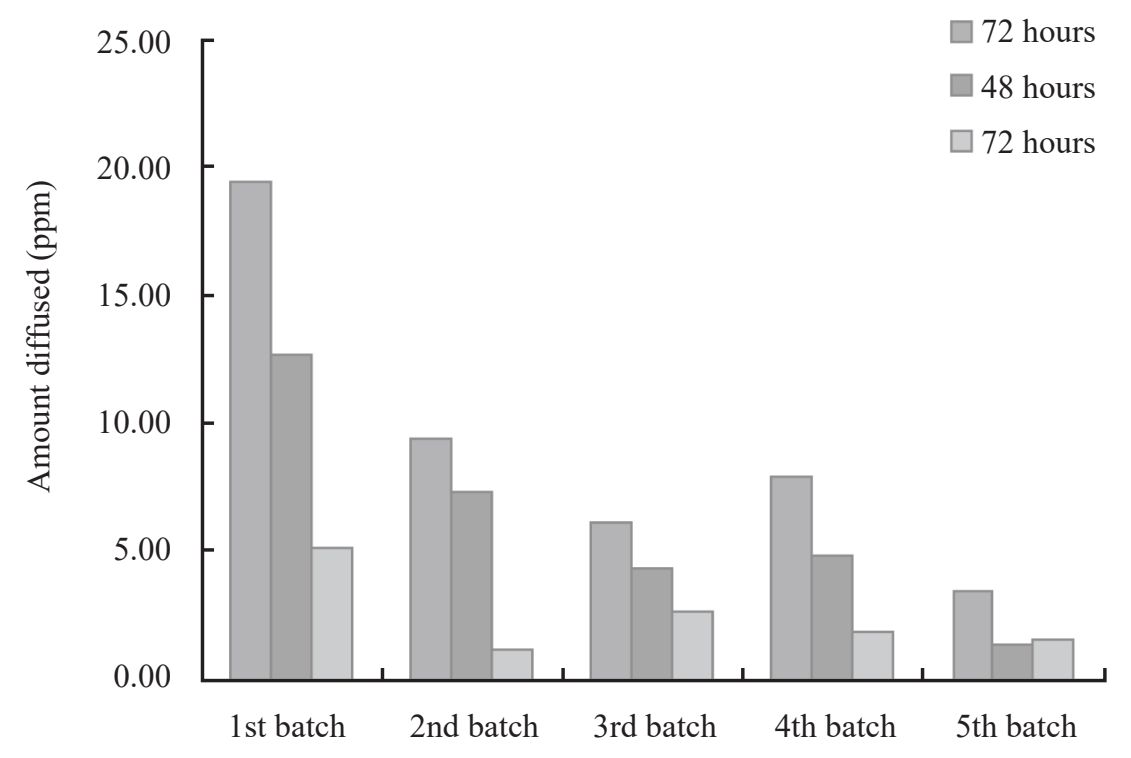

Figure 5. Effect of changing the medium on the amount of 2-naphthol diffusion.

from figure and table that the plots appeared linear for up to $16 \%$ of 2-naphthol release and the regression values were above 0.97 . The linear relationship indicated that the rate of the 2-naphthol diffusion of the biocomposites was non-dependent on the amount of 2-naphthol available for diffusion from the biocomposites.
When the diffusion data obtained were fitted using the Higuchi square root equation, it was evident from figure as well as table that a linear relationship was found in all biocomposites and the regression values were 0.98 and above indicating that the 2-naphthol 
release process was diffusion controlled. Referring to Table 2 the slope of the Higuchi curve was found to increase with the increase in chitosan content suggesting that the 2-naphthol release was faster in high chitosan loading compared to low loading.

When the 2-naphthol diffusion behaviour was calculated by calculating the values of release exponent from the Ritger-Peppas equation, a good fit into the equation was also observed as shown in the $\mathrm{r}^{2}$ values of Table 2 . The values of release exponent (n) were found to be a function of polymer content and the values, being $<0.45$ for all biocomposites indicating that the 2-naphthol release mechanism followed the Fickian diffusion release. This kind of release characteristics could be attributed to the high viscosity of the polymers and increase of strong entanglements bonds between the polymers which increases the diffusion path length of the chitosan as well as greater resistance to erosion by the diffusion medium (Ureña-Amate et al.
2011). The deviation of $n$ value below indicated that it can also be due to the complexity of the biocomposites system with a high heterogeneity (Angadi et al. 2011).

Interpretations obtained from the study of the release of 2-naphthol from the biocomposites suggested that the main driving force for the release of 2-naphthol from the biocomposites was penetration of the release medium. Therefore, upon contact with the water, the water penetrated into the biocomposites via the channels created by the chitosan and the 2-naphthol release might have happed via diffusion through pores formed. When the matrices were placed in water, the biocomposites started to swell due to the nature of chitosan itself. Increasing chitosan content increased in release rate as calculated and shown in Figure 3 and also proven by the Higuchi equation. This is probably due to the increase in total porosity of the biocomposites as shown in SEM (published elsewhere).

Table 2. Kinetic mechanism of 2-Naphthol release from CTS-t-ENR biocomposites.

\begin{tabular}{|c|c|c|c|c|c|c|c|c|}
\hline \multirow{2}{*}{$\begin{array}{c}\text { Chitosan } \\
\text { loading } \\
\text { (phr) }\end{array}$} & \multicolumn{2}{|c|}{$\begin{array}{l}\text { Zero order } \\
Q=Q_{0}-k_{0} \mathrm{t}\end{array}$} & \multicolumn{2}{|c|}{ First order } & \multicolumn{2}{|c|}{ Higuchi } & Ritge & Ritger-peppas \\
\hline & $\mathrm{R}^{2}$ & $K_{0}$ & $\mathrm{R}^{2}$ & $K_{l}$ & $\mathrm{R}^{2}$ & $K_{H}$ & $\mathrm{R}^{2}$ & $n$ \\
\hline 0 & 0.97 & 0.079 & 0.93 & 0.003 & 0.99 & 2.19 & 0.98 & 0.071 \\
\hline 2.5 & 0.99 & 0.131 & 0.97 & 0.004 & 0.98 & 3.59 & 0.99 & 0.099 \\
\hline 5 & 0.99 & 0.131 & 0.97 & 0.003 & 0.99 & 3.59 & 0.99 & 0.081 \\
\hline 10 & 0.98 & 0.145 & 0.95 & 0.003 & 0.99 & 4.02 & 0.98 & 0.079 \\
\hline 15 & 0.98 & $\begin{array}{c}0.182 \\
3\end{array}$ & 0.94 & 0.003 & 0.99 & 5.07 & 0.97 & 0.084 \\
\hline
\end{tabular}


At higher loading of chitosan, the degree of swelling was higher, therefore bigger and more pores were created in the network structure allowing more 2-naphthol to be released. Hence, both the decreased tortuosity and increased porosity had contributed to the higher 2-naphthol release rate in the composite with high chitosan content. Composite with $0 \mathrm{phr}$ had the lower swelling ability and this exhibited smaller and fewer pores in its network which would be more difficult from the 2-naphthol to dissolve and diffuse. Hence the rate of release in $0 \mathrm{phr}$ was prolonged and almost completed within 360 hours. Unlike with chitosan loaded biocomposites, the release continued at a slower rate. Therefore it could be deduced that the composite with higher chitosan loading contributed to higher 2-naphthol release due to its porosity which were the factors determining the rate and the pattern of 2-naphthol release from the biocomposites.

\section{CONCLUSIONS}

It was found that the CTS-t-ENR biocomposites had a better adsorption capacity than chitosan by itself in 2-naphthol. Also, the absorption was influenced by the initial concentration. However, the 2-naphthol release increased with chitosan loading. The diffusion data fitted well with zero-order rate equation indicating that diffusion of 2-naphthol is non-dependent on the amount of 2-naphthol available. The Higuchi equation indicated that the 2-naphthol release process is a diffusion controlled.

\section{AKNOWLEDGEMENT}

The authors would like to thank the Universiti Sains Malaysia for providing the financial support, PRGS grant no. 1001/PKIMIA/842021. Dr Gunasunderi Raju is also grateful to the Malaysian Rubber Board for the fellowship scheme in pursuing her $\mathrm{PhD}$ study.

Date of receipt: August 2017 Date of acceptance: September 2017

\section{REFERENCES}

Angadi, S, Manjeshwar, L \& Aminabhavi, T 2011, 'Stearic acid-coated chitosanbased interpenetrating polymer network microspheres: controlled release characteristics', Industrial \& Engineering Chemistry Research, vol. 50, pp. 4504-4514.

Chandra, R \& Rustgi, R 1998, 'Biodegradable polymer', Progress in Polymer Science, vol. 23, pp. 1273-1335.

Costa, P \& Sousa Lobo, J 2001, 'Modeling and comparison of dissolution profiles', European Journal of Pharmaceutical Sciences, vol. 13, pp. 123-133.

Dutta, P, Dutta, J \& Tripathi, V 2004, 'Chitin and chitosan:chemistry, property and application', Journal of Scientific and Industrial Research, vol. 63, pp. 20-31.

Gerstl, Z, Nasser, A \& Mingelgrin, U 1998, 'Controlled release of pesticides into soils from clay-polymer formulations', Journal of Agricultural and Food Chemistry, vol. 46, no. 9, pp. 3797-3802.

Hameed, B \& Hakimi, H 2008, 'Utilization of durian (Durio zibethinus Murray) peel as low cost sorbent for the removal of acid dye from aqueous solutions', Biochemical Engineering Journal, vol. 39, no. 2, pp. 338-343.

Ismail, H, Shaari, S \& Othman, N 2011, 'The effect of chitosan loading on the curing characteristics, mechanical and 
morphological properties of chitosan-filled natural rubber (NR), epoxidised natural rubber (ENR) and styrene-butadiene rubber (SBR) compounds', Polymer Testing, vol. 30, no. 7, pp. 784-790.

Karickhoff, S, Brown, D \& Scott, T 1979, 'Sorption of hydrophobic pollutants on natural sediments', Water Research, vol. 13, no. 3, pp. 241-248.

Letwattanaseri, T, Ichikawa, N, Mizoguchi, T, Tanaka, Y \& Chirachanchai, S 2009, 'Epoxidized natural rubber bionanocomposite: a model case of bionanocomposite using nanofibrous chitosan and its consequent functional properties', Chemistry Letters, vo. 38, no. 8, pp. 798-799.

Li, J, Yao, J, Li, Y \& Shao, Y 2012, 'Controlled release and retarded leaching of pesticides by encapsulating in carboxymethyl chitosan /bentonite composite gel', Journal of Environmental Science and Health, Part B, vol. 47 , no. 8 , pp. 795-803.

Lobo, F, Aguirre, CD, Souza, P M, Grillo, R, de Melo, N, Rosa, A. et al. 2012, 'Preparation and characterization of polymeric microparticles used for controlled release of ametryn herbicide', Herbicides-Properties, Synthesis and Control of Weeds, ed. M. N. Hasaneen, pp. 1-16.

Mas Haris, M \& Raju, G 2014, 'Preparation and characterization of biopolymers comprising chitosan-grafted-ENR via acid-induced reaction of ENR50 with chitosan', eXPRESS Polymer Letters, vol. 8, no. 2, pp. 85-94.
Raju, G, Mas Haris, MA, Rashid, A, Azahari, B \& Noorsal, K 2013, 'Effect of chitosan loading on mechanical properties, water uptake and toluene absorbency of high and low molecular weight ENR50', Journal of Rubber Research, vol. 16, no. 3, pp. 179-194.

Riyajan, S-A \& Sukhlaaied, W 2013, 'Effect of chitosan content on gel content of epoxized natural rubber grafted with chitosan in latex form', Materials Science and Engineering: C, vol. 33, no. 3, pp. 1041-1047.

Sopeña, F, Maqueda, C \& Moril, E 2009, 'Controlled release formulations of herbicides based on micro-encapsulation', Ciencia e Investigación Agrarian, vo. 35, no. 1, pp. 27-42.

Teixeira, M, Paterson, W, Dunn, E, Li, Q, Hunter, B \& Goosen, M 1990, 'Assessment of chitosan gels for the controlled release of agrochemicals', Industrial \& Engineering Chemistry Research, vol. 29, no. 7, pp. 1205-1209.

Ureña-Amate, M, Boutarbouch, N, SociasViciana, M \& González-Pradas, E 2011, 'Controlled release of nitrate from hydrotalcite modified formulations', Applied Clay Science, vol. 52, pp. 368-373.

Wang, H.-L, Liu, S. - Q \& Zhang, X. -Y 2009, 'Preparation and application of sustained release microcapsules of potassium ferrate(VI) for dinitro butyl phenol (DNBP) wastewater treatment', Journal of Hazardous Materials, vol. 169, pp. 448-453. 


\title{
Preparation and Characterisation of Crosslinked Natural Rubber (SMR CV 60) and Epoxidised Natural Rubber (ENR-50) Blends
}

\author{
M. SASITARAN ${ }^{1}$, S. MANROSHAN ${ }^{2}$, C.S. LIM $^{3}$, B. N. KRISHNA VENI ${ }^{2}$, S.K. ONG ${ }^{4}$ \\ AND R. GUNASUNDERI ${ }^{1}$
}

\begin{abstract}
In this study, the influence of di(tert-butylperoxyisopropyl)benzene (DTBPIB) on the properties of natural rubber (NR) blend with epoxidized natural rubber (ENR) was determined. Fourier transform infrared spectroscopy with attenuated total reflectance analysis and gel content confirmed crosslinking occurred in the rubber blends in the presence of peroxide DTBPIB percentage. Studies including tensile properties, dynamic mechanical properties, thermogravimetric analysis (TGA) and water absorptivity showed the changes in properties of the crosslinked NR/ENR blends. Tensile properties analysis disclosed the improvements in the modulus at 300\% elongation and tensile strength with increasing NR ratios. Dynamic mechanical analysis revealed the blends to be incompatible and immiscible, with ENR showing a more viscous behaviour compared to the polymer blends. Thermal properties improved by blending NR with ENR as the onset temperature of NR/ENR: $50 / 50$ was higher than pure NR by approximately $10^{\circ} \mathrm{C}$ and ENR by approximately $2^{\circ} \mathrm{C}$. Water absorptivity experiment revealed a two-fold reduction in the presence of crosslinking for all blend ratios.
\end{abstract}

Key words: Natural rubber; epoxidized natural rubber; polymer blend; peroxide crosslinking agent

The advancement in polymer research has brought about the idea of blending polymers. Blending is a process of mixing two or more polymers creating a product which has the combined properties of the individual polymers (Notario, Pinto \& Rodriguez-Perez 2016; Ramesh 2016). Looking at this, many researchers have diverged their interest from developing novel polymeric compounds through synthesis to blending. Hence, number of studies have been conducted in recent years on blending various polymers which includes rubber-rubber blend, plastic-plastic blend and rubber-plastic blend (Vinod, Varghese \& Kuriakose 2002; Arroyo et al. 2007; Wan Yunus et al. 2013; Notario, Pinto \& RodriguezPerez 2016; Ramesh, 2016). Improvement in thermal, physical and mechanical properties are demonstrated by altering the composition and formulation of blends (Park 2001; De et al. 2013; Díaz, Katsarava \& Puiggalí 2014; Ramesh 2016). By blending, the technical and economic difficulties faced during the synthesis of new homogenous polymers are

\footnotetext{
${ }^{1}$ School of Distance Education, Universiti Sains Malaysia, 11800 Pulau Pinang, Malaysia

${ }^{2}$ Rubber Research Institute of Malaysia, Malaysian Rubber Board, 47000 Sg. Buloh, Malaysia

${ }^{3}$ School of Pharmacy, International Medical University, 57000 Bukit Jalil, Malaysia

${ }^{4}$ Universiti Kuala Lumpur, Malaysian Institute of Chemical and Bioengineering Technology, 78000 Alor Gajah, Melaka, Malaysia

*Corresponding author (e-mail: manroshan@lgm.gov.my)
} 
avoided as this process is more cost effective and time-saving (Arayapranee \& Rempel 2007). Therefore, polymer blending has been recognized as the most promising method to generate new material with tailored individual properties (Ulbricht 2006; Mitragotri \& Lahann 2009).

Malaysia is one of the leading producers of natural rubber (NR). Natural rubber is classified as an elastomer due to the presence of the polyisoprene backbone (Vinod, Varghese \& Kuriakose 2002; Khimi \& Pickering 2015). NR has been widely used in various applications due to its outstanding properties such as high tensile strength, resilience, toughness and good processing characteristic (Gurunathan, Mohanty \& Nayak 2015; Pal \& Panwar 2017). However, there are some limitations to NR properties which includes hardness, modulus, and abrasion resistance that need to be improved for it to be utilized in some specific application (Gurunathan, Mohanty \& Nayak 2015). Moreover, degradation by heat and ozone, high gas permeability and low oil resistance of NR have limited its applications (Wang et al. 2016). Studies reported that blending NR with ENR can be an effective solution to improve the properties for being used in widespread applications (Arroyo et al. 2007; Gurunathan, Mohanty \& Nayak 2015; Wang et al. 2016; Pal \& Panwar 2017).

ENR is produced by modifying NR via epoxidation where the epoxy rings are introduced on the NR backbone and at the same time reduces the number of double bonds (Arroyo et al. 2007). The polarity of the modified polymer depends on the epoxidation level. ENR has been reported to be compatible with other polar polymers (Varghese, KargerKocsis \& Gatos, 2003; Guo et al. 2004;
Rajasekar et al. 2009). ENR has been known since 1992 and is commercially available since the past decade. Currently, Malaysian Rubber Board is producing two grades of ENR (i.e. ENR 25 and ENR 50) with the trade name EKOPRENA. ENR 50 is chemically modified from 1,4-polyisoprene rubber and has some distinct properties such as low air permeability, oil resistance, and lower wet grip compared to synthetic rubber (Vinod, Varghese \& Kuriakose 2002; Gurunathan, Mohanty \& Nayak 2015). Thus, blending NR with ENR is bearing interest to improve stiffness, processibility, resilience and minimizing the damping property of polymers (Imbernon \& Norvez 2016). However, polymer blending has its drawbacks as well. Blending immiscible polymers can result in phase separation of the product, which requires a additional component as a mediator, such as a crosslinking agent to facilitate an interaction between the phases (Ismail, Nordin, 2002; Imbernon \& Norvez 2016).

Crosslinking agents react with polymers either by physical and/or chemical means (Benbettaïeb et al. 2016). The incorporation of a crosslinking agent in polymer blending forms three-dimensional network by generating crosslinks, branching \& extension of the chains (Pedernera \& Sarmoria 1999). Thus, the application of a crosslinking agent in NR blends with ENR might improve strength, stiffness and thermal stability of NR and/or ENR besides restricting water absorptivity of the blend. It is, therefore, the present work aims is to study the blending of Standard Malaysian Rubber (SMR CV 60) with ENR 50, with DTBPIB acting as the crosslinking agent. The resulting blends were characterized for the functional groups, crosslinking degree, tensile properties, thermal stability and water absorptivity. 


\section{EXPERIMENTAL}

\section{Materials}

Malaysian Rubber Board supplied NR grade SMR CV 60 [Mooney viscosity, ML(1+4) $\left.100^{\circ} \mathrm{C}=60\right]$ and $\mathrm{ENR}(50$ mole $\%$ epoxidation $)$. The crosslinking agent, DTBPIB, trade name Luperox ${ }^{\circledR}$ F40 (Figure 1) was purchased from Sigma-Aldrich Chemicals, England, whereas Xylene (analytical grade) was obtained from HmbG, Chemicals, Germany.

\section{METHODOLOGY}

\section{Sample Preparation}

Blending process was initiated by masticating $20 \mathrm{~g}$ of NR using Thermo Haake Polydrive internal mixer, operating at a temperature of $60^{\circ} \mathrm{C}$ with the rotor speed of 50 rotations per minute (rpm) for $2 \mathrm{~min}$. After masticating the NR, $20 \mathrm{~g}$ of ENR 50 was admixed into the mixing chamber. Blending was continued for another 2 min to form NR/ENR: 50/50 blend. The crosslinking agent (DTBPIB) was fixed at $5 \mathrm{phr}$ (parts per hundred rubber). Lastly, DTBPIB was added, and mixing was continued for another additional $6 \mathrm{~min}$. The blends were moulded using compression moulding with a mould of dimension $100 \mathrm{~mm} \times 100 \mathrm{~mm} \times 1 \mathrm{~mm}$, a pressure of $150 \mathrm{~kg} / \mathrm{cm}^{2}$ and cured at $160^{\circ} \mathrm{C}$ for $10 \mathrm{~min}$. The crosslinking temperature used was based on investigations done on peroxides (Thitithammawong, Nakason, Sahakaro \& Noordermeer 2007; Thitithammawong, Nakason, Sahakaro \& Noordermeer 2007). Cooling was carried out using a cold press at $30^{\circ} \mathrm{C}$ for $10 \mathrm{~min}$. Other NR/ENR blends were prepared by changing the mass ratio of NR to ENR to achieve blend ratio of $0 / 100,25 / 75$, $75 / 25$ and $100 / 0 \%$ by weight. Similarly, the above NR/ENR blends were also prepared without DTBPIB.

\section{Determination of Functional Groups}

Fourier transform infrared spectroscopy with attenuated total reflectance analysis (FTIRATR) was carried out using a Perkin Elmer Spectrum 1000 series spectrophotometer. Thin films of all NR/ENR blend ratios with and without DTBPIB were analysed. The infrared spectra of the samples were recorded in the frequency range of $600 \mathrm{~cm}^{-1}$ to $4000 \mathrm{~cm}^{-1}$.

\section{Determination of Crosslinking Degree}

Gel content analysis was used to determine the crosslinking degree of NR/ENR blends with and without DTBPIB. The thin films of all blend ratios were cut into tiny pieces weighing approximately $0.5 \mathrm{~g}$ each and packed in mesh pockets, pre-weighed and labelled. The weight of the mesh pockets with the samples was recorded and the samples were refluxed using xylene in a soxhlet extractor for $24 \mathrm{~h}$. After 24 $\mathrm{h}$ the meshes were removed from the roundbottom flask and dried to a constant weight in an oven at $60^{\circ} \mathrm{C}$. The weight of samples after extraction was recorded and the percentage gel content was calculated using Equation 1:

Gel content $(\%)=\frac{A}{B} \times 100$

Where, $A$ is the weight of the sample after extraction and $B$ is the initial weight of the sample.<smiles>CC(C)(C)OOC(C)(C)c1ccc(C(C)(C)OOC(C)(C)C)cc1</smiles>

Scheme 1. The chemical structure of Luperox ${ }^{\circledR}$ F40 (Mammadov et al. 2012). 


\section{Determination of Tensile Properties}

Tensile test on NR/ENR blends was carried out according to ASTM D638M-98 with a crosshead speed of $50 \mathrm{~mm} / \mathrm{min}$ and a static load cell of 100 $\mathrm{kN}$ using an Instron 4302 series IX, Universal Testing Machine. Each sample's width and thickness were measured prior to testing. The mean value of at least five specimens for each sample was reported.

\section{Determination of Thermal Stability}

The thermal stability of the blends was studied using two techniques, namely: dynamic mechanical analysis and thermogravimetric analysis. For dynamic mechanical analysis, the samples were cut into a rectangular shape (10 $\mathrm{mm} \times 40 \mathrm{~mm} \times 1 \mathrm{~mm})$ and placed in the rotating measuring head of a Mettler Toledo DMA 1 analyser under tension mode with an oscillating frequency of $1 \mathrm{~Hz}$. The dynamic storage modulus (E'), loss modulus (E") and mechanical loss factor $(\tan \delta)$ were recorded in the temperature range of $-100^{\circ} \mathrm{C}$ to $60^{\circ} \mathrm{C}$ at the heating rate of $5^{\circ} \mathrm{C} / \mathrm{min}$. Whereas, thermal decomposition of NR/ENR blends were studied using a Perkin Elmer TGA 7 analyser. The samples were heated from $30^{\circ} \mathrm{C}$ to $800^{\circ} \mathrm{C}$ at a rate of $20^{\circ} \mathrm{C} / \mathrm{min}$ under a nitrogen atmosphere with nitrogen flow rate of $20 \mathrm{ml} / \mathrm{min}$. The onset and maximum degradation temperatures were recorded and plotted as a function of time.

\section{Determination of Water Absorptivity}

The water absorptivity of NR/ENR samples with and without DTBPIB was measured by first cutting the samples to the nearest $1 \mathrm{~g}$ and immersing them in distilled water maintained at room temperature for $840 \mathrm{~h}$ (35 days). The samples from each blend ratio were removed from the distilled water, gently blotted to dry with tissue paper to remove the excess water present on the surface of the samples. The weight of the samples was recorded and dried to constant weight in an oven at a temperature of $60^{\circ} \mathrm{C}$ for $24 \mathrm{~h}$. The percentage of water absorption was calculated using Equation 2:

Water absorptivity $(\%)=\frac{m_{2}-n_{1}}{m^{1}} \times 100$

where, $m_{2}$ is the weight of the samples before drying and $m_{1}$ is the weight of the samples after drying.

\section{RESULTS AND DISCUSSION}

\section{Functional Groups}

The FTIR-ATR spectra of NR/ENR blends with and without DTBPIB are shown in Figure 1. The spectrum of blend NR/ENR: 100/0 [Figure 2(a)] shows strong peaks of unsaturated $\mathrm{C}=\mathrm{C}$ stretching and out-of-plane $\mathrm{C}-\mathrm{H}$ rocking at 1635 $\mathrm{cm}^{-1}$ and $1025 \mathrm{~cm}^{-1}$. On the other hand, medium peaks at $1450 \mathrm{~cm}^{-1}$ and $1375 \mathrm{~cm}^{-1}$ contribute to $-\mathrm{CH}_{2^{-}}$and $-\mathrm{CH}_{3^{-}}$bending. The intensity of peaks at $1635 \mathrm{~cm}^{-1}$ and $1025 \mathrm{~cm}^{-1}$ reduced drastically with crosslinking due to the radical reaction of DTBPIB with the unsaturated carbons of NR (P. Phinyocheep 2014). Peaks at $2935 \mathrm{~cm}^{-1}, 2864 \mathrm{~cm}^{-1}$ and $2840 \mathrm{~cm}^{-1}$ attributed to $\mathrm{C}-\mathrm{H}$ stretching and the peak at $830 \mathrm{~cm}-1$ indicating $\mathrm{C}-\mathrm{H}$ bending attached to unsaturated carbon (Kochthongrasamee, Prasassarakich \& Kiatkamjornwong 2006; Anancharungsuk et al. 2007). This proves that crosslinking has occurred in NR.

Figure 2(b) shows the NR/ENR: 0/100 spectrum with and without crosslinking, respectively. The peaks at $1110 \mathrm{~cm}^{-1}$ and 870 $\mathrm{cm}^{-1}$ indicate the epoxy ring and $\mathrm{C}-\mathrm{H}$ bending attached to the epoxy ring, (Mas Haris \& Raju 2014) whereas, strong peaks at $1499 \mathrm{~cm}^{-1}$ and $1377 \mathrm{~cm}^{-1}$ can be related to $-\mathrm{CH}_{2^{-}}$and $-\mathrm{CH}_{3^{-}}$ bending. A short, broad peak of $\mathrm{C}=\mathrm{C}$ stretching 

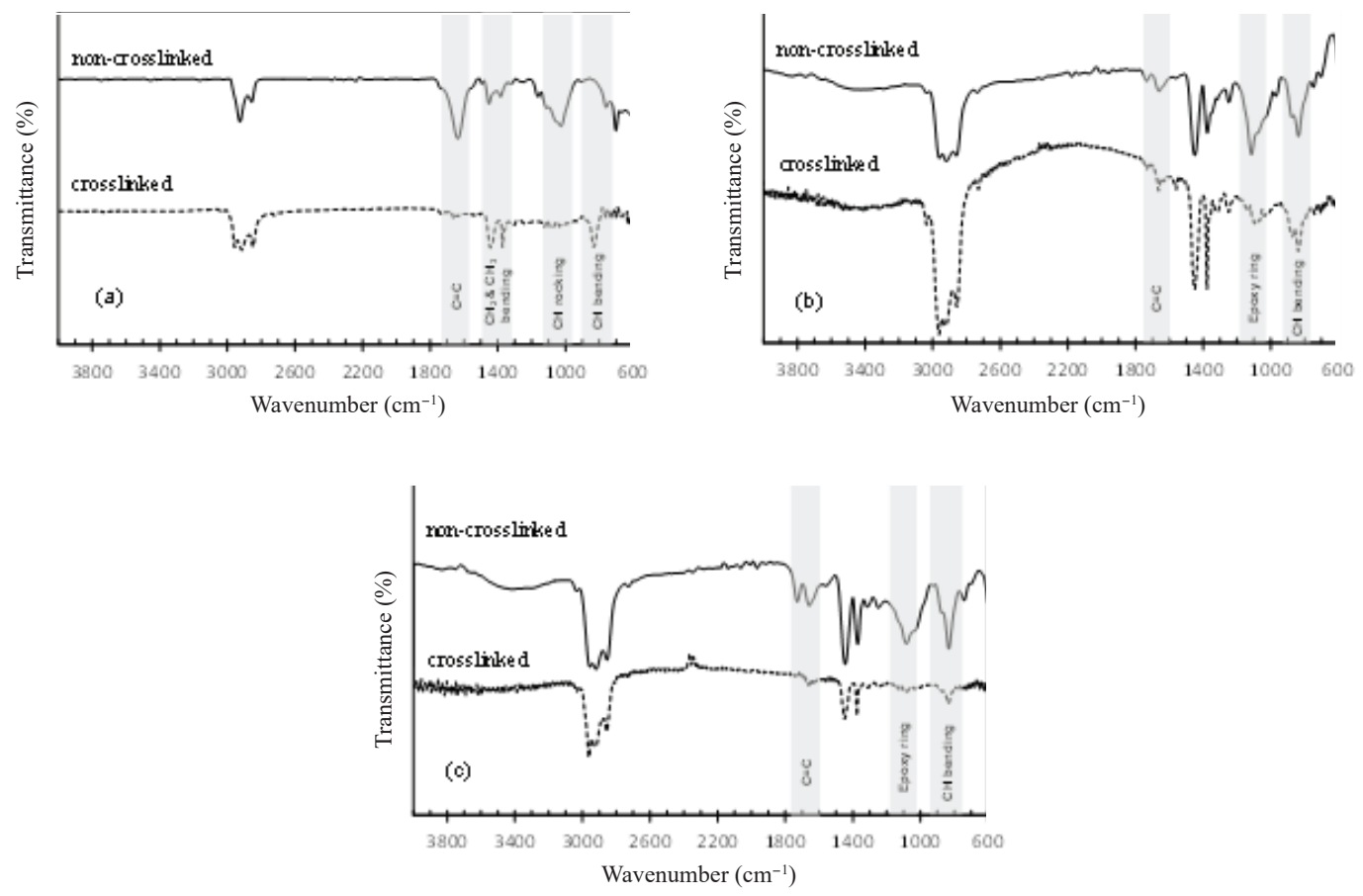

Figure 1. The FTIR spectra of NR/ENR blends with ratios of 100/0 (a), 0/100 (b) and 50/50 (c).

and $\mathrm{C}-\mathrm{H}$ bending attached to unsaturated carbon are also observed at $1663 \mathrm{~cm}^{-1}$ and $830 \mathrm{~cm}^{-1}$. The intensities at $1110 \mathrm{~cm}^{-1}$ and $870 \mathrm{~cm}^{-1}$ which are observed in NR/ENR:0/100 reduced after crosslinking, which might be due to the opening of the epoxy ring forming crosslink bridges. Subsequently, reduction in $\mathrm{C}=\mathrm{C}$ stretching and out-of-plane $\mathrm{C}$-H suggest that crosslinking has also occurred at the $\mathrm{C}=\mathrm{C}$ double bond.

Figure 1(c) shows the NR/ENR:50/50 spectrum with and without crosslinking. In the presence of crosslinking, the peaks of th epoxy ring at $1080 \mathrm{~cm}^{-1}$ and $\mathrm{C}-\mathrm{H}$ bending attached to the epoxy ring at $870 \mathrm{~cm}^{-1}$ were observed to reduce drastically. The same was observed for the $\mathrm{C}=\mathrm{C}$ stretching and $\mathrm{C}-\mathrm{H}$ bending attached to unsaturated carbon at peaks of $1653 \mathrm{~cm}^{-1}$ and $831 \mathrm{~cm}^{-1}$. From these results, it is evident that crosslinking has taken place in the NR/ ENR blends.

\section{Crosslinking Degree}

Figure 3 shows the effect of NR/ENR blend ratio on the gel content with and without DTBPIB.

The solvent (xylene) was observed to dissolve both NR and ENR, and their respective blends without crosslinking as the gel content obtained were almost $0 \%$. However, once crosslinked, the gel content increased. This proved the formation of three-dimensional networks between the chains in the rubbers. NR/ENR: 100/0 with crosslinking showed the highest gel content of $96 \%$ whereas NR/ ENR: 0/100 with crosslinking showed the least gel content of $75 \%$. The gel content between chains of NR was higher than between the chains of ENR and this could be due to the percentage of epoxy rings in the ENR forming less crosslinking bridges between the chains compared to the double bonds present in the isoprene of NR. 


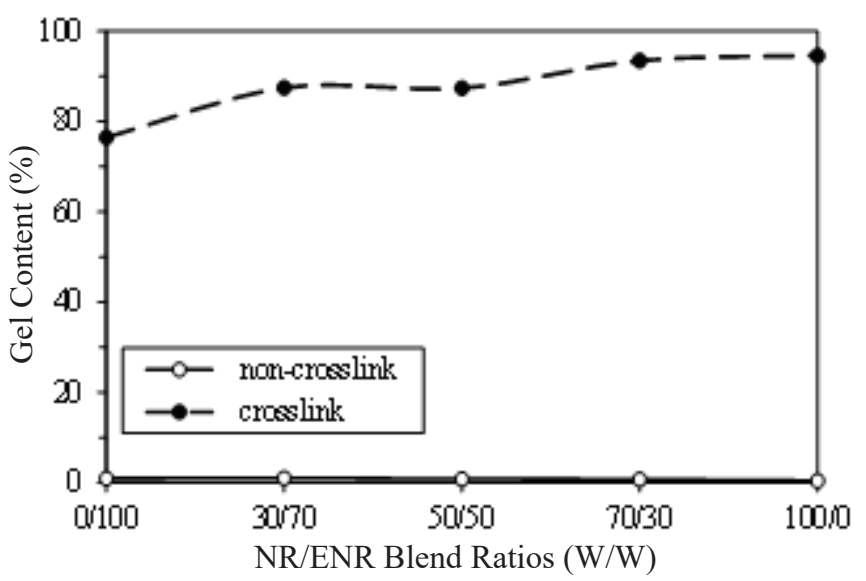

Figure 2. The percentage gel content of NR/ENR blends with and without DTBPIB.

\section{Tensile Properties}

Tensile modulus, tensile strength, and elongation at break of NR/ENR blends with and without DTBPIB are shown in Figure 3.

The tensile modulus [Figure 3(a)] and strength [Figure 3(b)] without crosslinking were independent of the blend ratios. This could be due to the absence of linkages between chains upon which application of minimal force resulted in the stretching of the films. On the other hand, elongation at break (EB) [Figure 3(c)] was reduced with increasing NR loading, due to the carbon-carbon double bonds that are stronger and more constraining upon stretching compared to the epoxy rings of ENR.

Upon the introduction of crosslinks, both tensile modulus at 300\% elongation (M300) and tensile strength increased for all blend ratios. The crosslinking results in stiffer and stronger blends due to the three-dimensional network formed which limited the molecular chain mobility of the polymer blend. Thus higher force was required to stretch the blend. It was also observed that when the NR loading increased, the blend showed higher tensile modulus and strength. This was because NR had more allylic carbon as compared to ENR. Therefore, with the higher amount of allylic carbon, a higher degree of crosslinking might be expected. This was consistent with the gel content results reported earlier.

The opposite was however observed for elongation at break. Although no significant changes were observed for the blends, changes were observed for the pure polymers with a reduction in EB for ENR (NR/ENR: 0/100) and an increase in the EB for NR (NR/ENR: 100/0). The poorer EB for ENR compared to NR was due to the three-dimensional network formation which limited molecular chain mobility. However, the scission of a much stiffer carbon double bond to form crosslinking could have increased the chain mobility in NR. The results were consistent with the FTIR-ATR and gel content reported earlier.

\section{Dynamic Mechanical Analysis}

The storage (E') and loss (E") moduli of the blends as a function of temperature in the presence of DTBPIB are shown in Figure 4. 

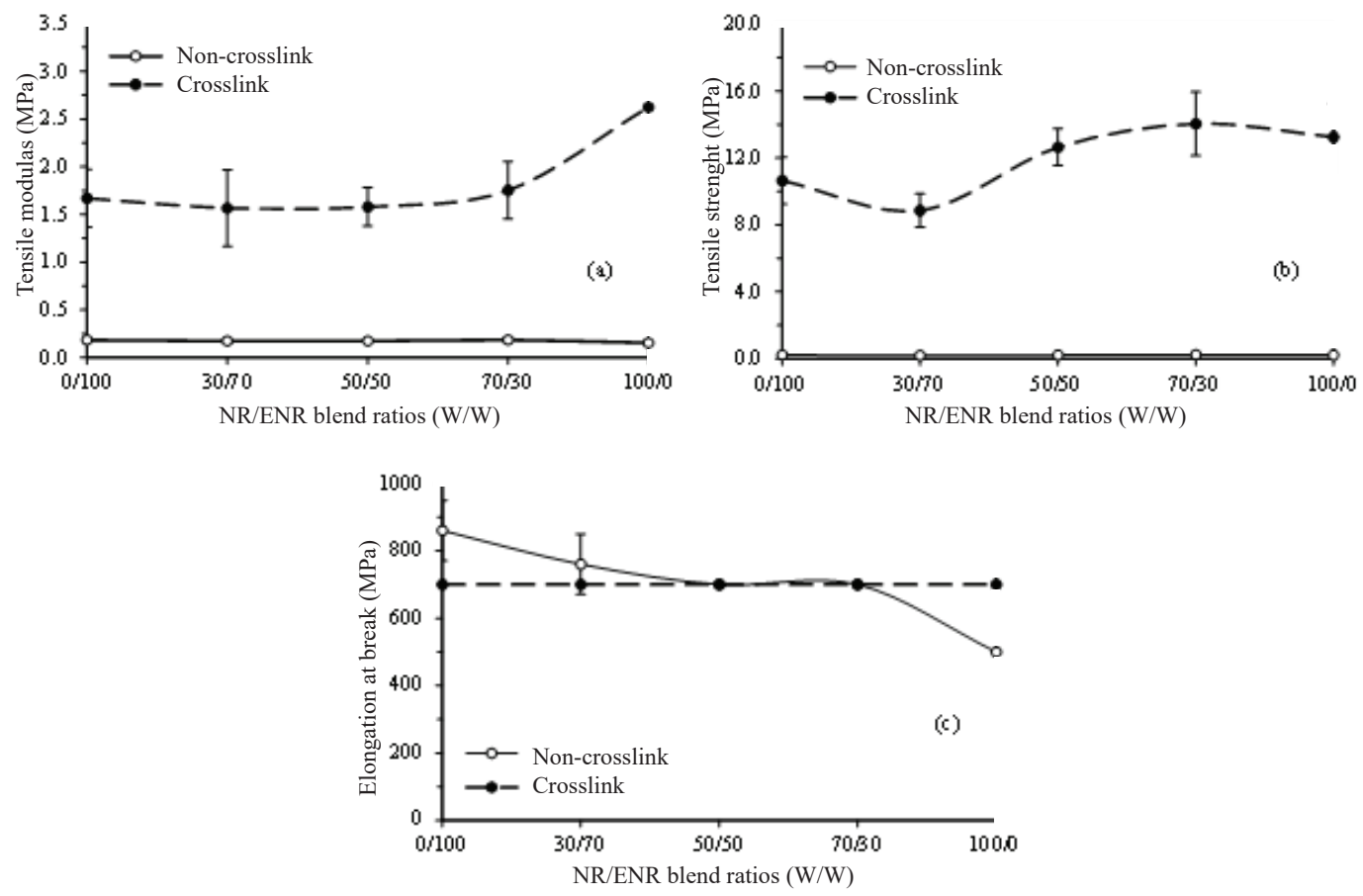

Figure 3. The tensile modulus at $300 \%$ elongation (a), tensile strength (b) and elongation at break (c) of NR/ENR blends.

In general, the changes in E' and E" are a direct representation of the intermolecular and intramolecular interactions between polymers. At low temperature, the moduli did not show much change as the deformation was primarily elastic due to the less molecular motion. As the temperature was increased, E' reduced reaching a minimum with no further changes. On the other hand, E" increased reaching a maximum before decreasing. The increase in E" was due to Brownian motion and stress relaxation acting together whereas the decrease in E" after that was due to the free movement of the molecular segments of the polymer (Sin et al. 2014). From the results in Figure 4, pure polymers (Figure 5 (a and e)) showed a single E" peak whereas two E" peaks were observed for the blends [Figure 5 (b, c and d)]. The two E" peaks show incompatibility between the polymers. However, as the NR content was increased, the distance between the two peaks reduced. In order to elucidate the results further, $\tan \delta$ was used (Figure 5).

Using the $\tan \delta$ value versus temperature plot in Figure 5(a), information on glass transition temperature ( $\mathrm{Tg}$ ) and damping were obtained. The $\mathrm{Tg}$ was indicated by the number of peaks and from Figure 6 (a), it was evident that both pure polymers (NR and ENR) showed single peaks indicating one $\mathrm{Tg}$ value whereas the blends showed two peaks indicating two Tg values. Damping, on the other hand, was observed from the $\tan \delta$ values. At their respective Tg, ENR showed $\tan \delta$ of 2 whereas NR showed $\tan \delta$ of 2.8. As the $\tan \delta$ was higher for NR, NR showed higher damping compared to ENR at Tg. Blending both polymers resulted in a significant reduction in damping as indicated by the reduced $\tan \delta$ 

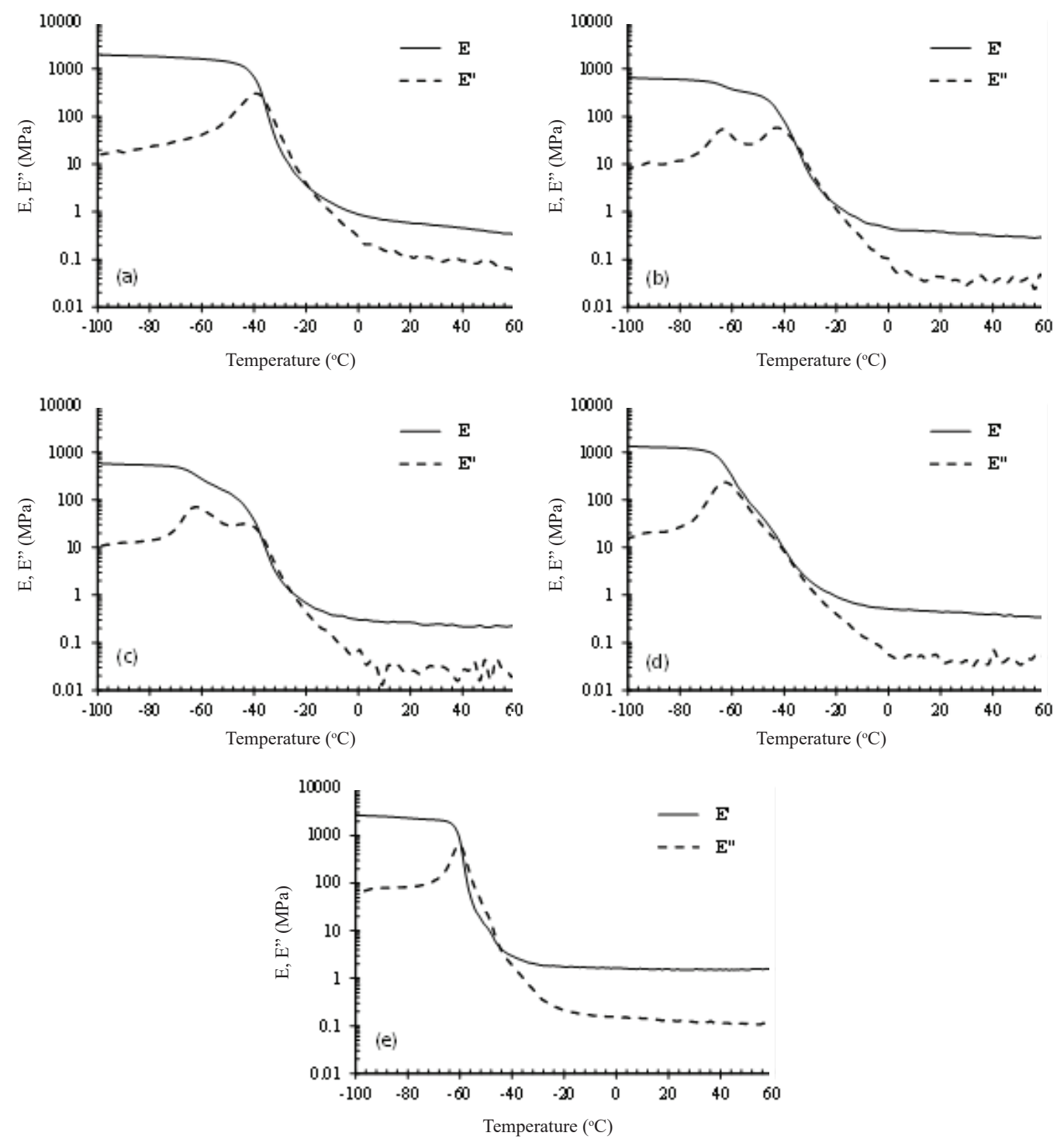

Figure 4. The effect of temperature on the storage (E') and loss (E") moduli of NR/ENR blend in the presence of DTBPIB for blend ratios of (a) 0/100, (b) 30/70, (c) 50/50, (d) 70/30, (e) 100/0.

values. Nevertheless, $\tan \delta$ values of the blends increased with increasing ENR content, and this was associated with the increase in interfacial bonding due to the increased crystallinity of blends (Chandra, Singh \& Gupta 1999; Sin et al. 2014).

At room temperature $\left(30^{\circ} \mathrm{C}\right)$, a change in the damping behaviour was observed for all blends (Figure 5(b). The damping of pure ENR
(ENR/NR:100/0) was double the damping of pure NR (ENR/NR:0/100). The blending of NR to ENR at all blend ratios also resulted in a reduction in damping as the $\tan \delta$ approached values of pure NR (in the range of 0.08 ). The higher damping of pure ENR was probably due to the presence of lesser allylic carbons and crosslinks compared to NR resulting in the higher molecular chain mobility. 


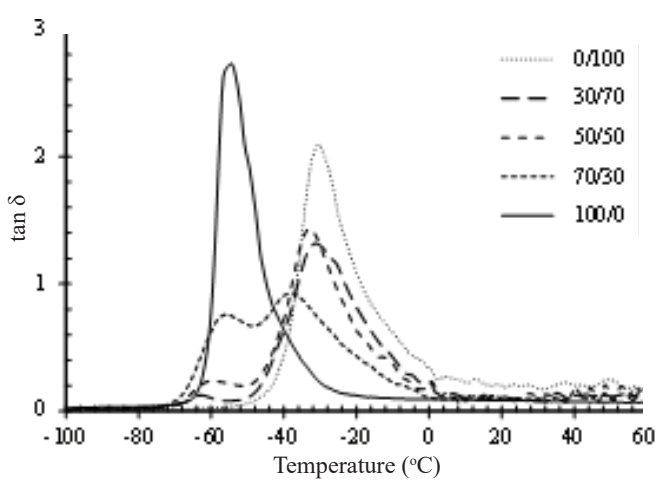

(a)

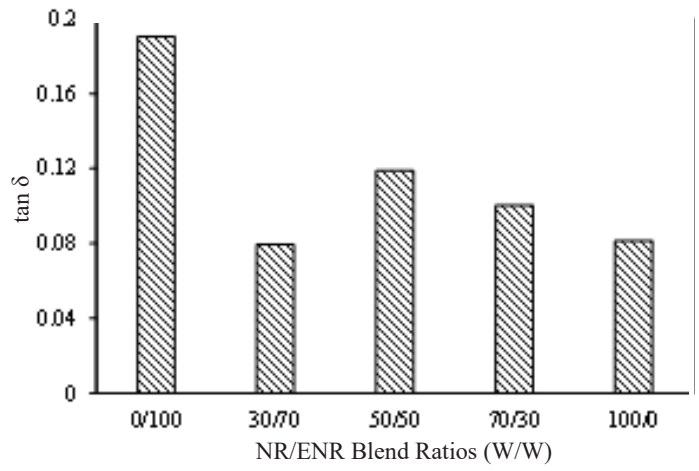

(b)

Figure 5. Tan $\delta$ of crosslinked NR/ENR blends as a function of temperature (a) and at $30 o C(b)$.

\section{Thermogravimetric Analysis}

The TGA and DTG curves of NR/ENR blends in the presence of DTBPIB are shown in Figure 6. From the thermograms, the information on the onset temperature of degradation and maximum decomposition temperature were obtained, and the results are summarised in Table 1 .

From Table 1, it is evident that blending NR with ENR improved the thermal stability of the blends as the onset temperature of NR/ ENR: 50/50 was higher than for pure NR and
ENR. However, the maximum decomposition temperature was slightly lower than pure ENR. In comparison to the NR, ENR showed an increase of $8^{\circ} \mathrm{C}$ and $10^{\circ} \mathrm{C}$ in onset and maximum decomposition temperature, respectively. NR exhibits low thermal stability and degrades in the presence of high temperature due to the $\mathrm{C}=\mathrm{C}$ in the backbone (Piya-Areetham, Rempel \& Prasassarakich 2014). This results in NR to be thermally less stable than ENR and blending NR with ENR enhanced the thermal properties of the blends.
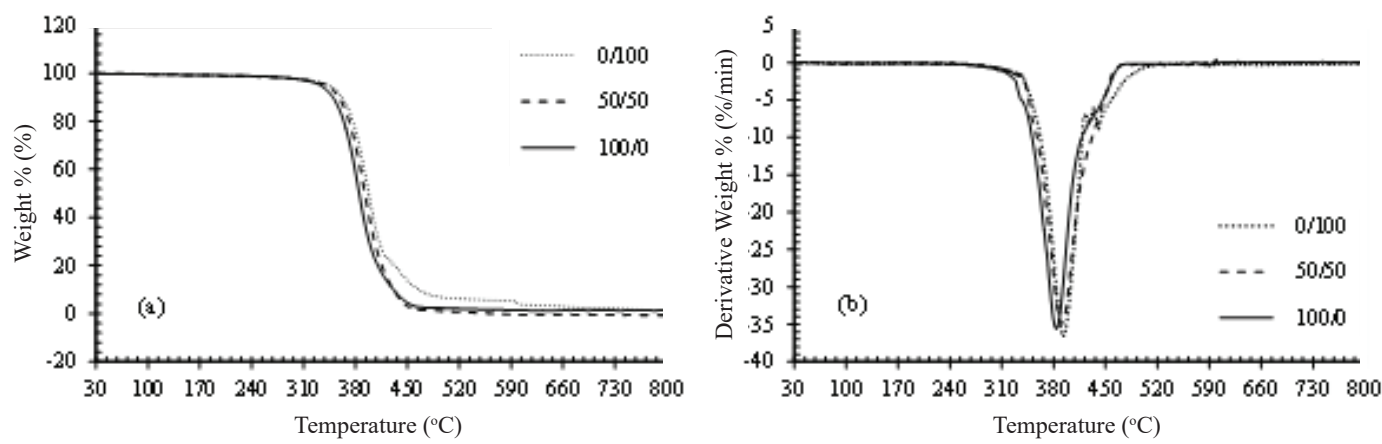

Figure 6. The TGA (a) and DTG spectra (b) of NR/ENR blends in the presence of DTBPIB. 
Table 1. Onset and maximum decomposition temperature of NR/ENR Blend with DTBPIB.

\begin{tabular}{c|cc}
\hline \multirow{2}{*}{ NR/ENR Ratio } & \multicolumn{2}{|c}{ Temperature $\left({ }^{\circ} \mathrm{C}\right)$} \\
& Onset & Maximum decomposition \\
\hline $0 / 100$ & 365.4 & 392.1 \\
$50 / 50$ & 367.2 & 390.3 \\
$100 / 0$ & 357.5 & 382.9 \\
\hline
\end{tabular}

\section{Water Absorptivity}

Figure 8 shows the water absorptivity by NR/ENR blends with and without DTBPIB, measured for 35 days. In comparison to blends without DTBPIB, the blends with DTBPIB [Figure $8(\mathrm{~b})$ ] showed a $50 \%$ reduction in water absorptivity. The DTBPIB forms a three-dimensional network which hinders the penetration of water molecules into the network, therefore reducing the water absorptivity of the blends (Abdelmouleh et al. 2007).

The highest water absorptivity was observed for NR/ENR:0/100 blend ratios, with and without DTBPIB. This was due to the high polarity of ENR which exhibited hydrophilic (polar) nature. A reducing trend in water absorptivity could be seen in the blends with increasing NR ratio. Ultimately NR/ENR blend ratio of 100/0 showed the least water absorptivity owing to the hydrophobic (nonpolar) structure of NR.

\section{CONCLUSION}

NR and ENR blends were successfully prepared by melt blending method. The FTIR-ATR showed crosslinking which occured not only in the pure polymers but also in the blends. As a result, the percentage gel content of the NR/ENR blends was increased with a higher degree of crosslinking observed for blends with increasing ratio of NR. Similarly, the tensile modulus at $300 \%$ elongation and tensile strength of NR/ ENR blends also increased with crosslinking. However, no changes were observed in the
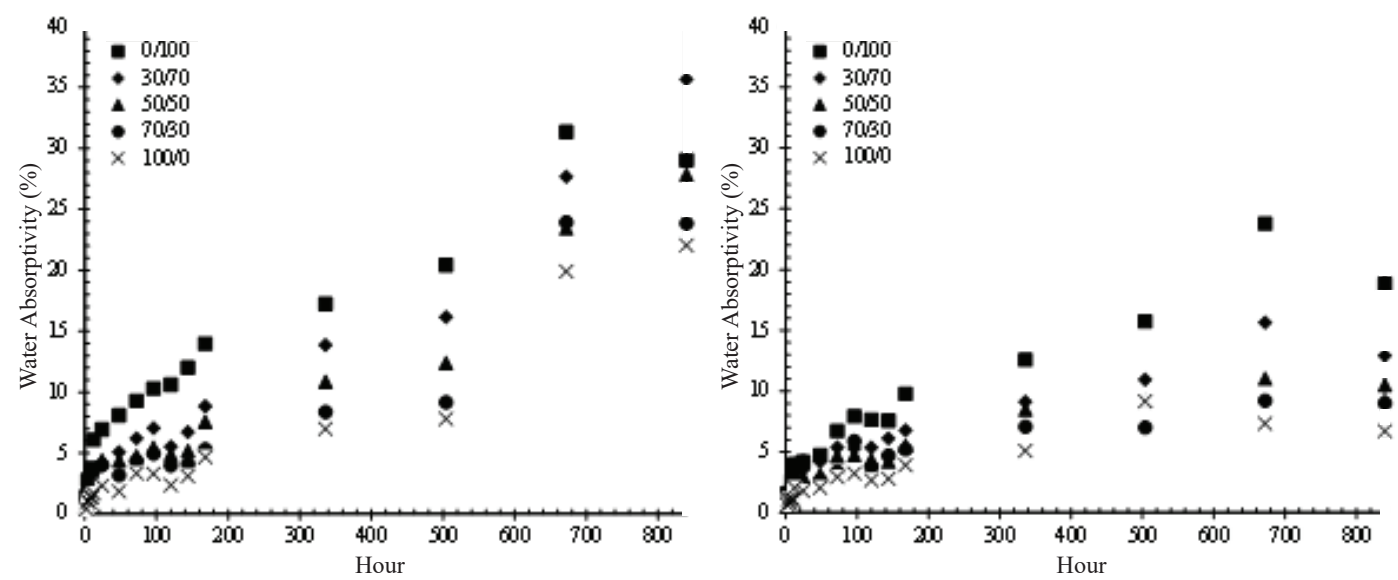

Figure 7. The water absorptivity of NR/ENR blends without DTBPIB (a) and with DTBPIB (b). 
elongation at break after crosslinking although a reduction in EB was observed in the absence of crosslinking with increasing NR loading. This was probably due to breaking of $\mathrm{C}=\mathrm{C}$ bonds to form $\mathrm{C}-\mathrm{C}$ linkages which were less constraining between NR polymers. Dynamic mechanical analysis revealed the blends which was immiscible due to the presence of two peaks which represented the individual polymers. At room temperature, ENR showed a more viscous behaviour which reduced with increasing NR loading. On the other hand, the thermal properties favoured ENR compared to $\mathrm{NR}$, as NR had more $\mathrm{C}=\mathrm{C}$ double bonds in the backbone which rendered a lower thermal stability. Therefore, blending ENR with NR improved the thermal properties of the NR/ ENR blend. In the absence of crosslinking, both polymers and their respective blends showed high water absorptivity with higher absorptivity favouring a higher ENR loading due to its polar nature. The introduction of polymer networks through crosslinking significantly reduced the water absorptivity.

Date of receipt: May 2017 Date of acceptance: October 2017

\section{REFERENCES}

Abdelmouleh, M. et al. 2007, 'Short naturalfibre reinforced polyethylene and natural rubber composites: Effect of silane coupling agents and fibres loading', Composites Science and Technology, vol. 67, no. 7-8, pp. 1627-1639.

Anancharungsuk, W. et al. 2007, 'Surface modification of natural rubber film by UVinduced graft copolymerization with methyl methacrylate', Journal of Applied Polymer Science, vol. 104, no. 4, pp. 2270-2276.
Arayapranee, W \& Rempel, GL 2007, 'Properties of NR / EPDM blends with or without methyl methacrylate-butadiene-styrene (MBS) as a Compatibilizer', International Journal of Materials \& Structural Reliability, vol. 5, no. 1, pp. 1-12.

Arroyo, M. et al. 2007, 'Morphology/behaviour relationship of nanocomposites based on natural rubber/epoxidized natural rubber blends', Composites Science and Technology, vol. 67, no. 7-8, pp. 1330-1339.

Benbettaïeb, N. et al. 2016, 'Tuning the functional properties of polysaccharideprotein bio-based edible films by chemical, enzymatic, and physical cross-linking', Comprehensive Reviews in Food Science and Food Safety, vol. 15, no. 4, pp. 739-752.

Chandra, R, Singh, S \& Gupta, K 1999, 'Damping studies in fiber-reinforced composites - a review', Composite Structures, vol. 46, no. 1, pp. 41-51.

De, D. et al. 2013, 'Reinforcing effect of reclaim rubber on natural rubber/polybutadiene rubber blends', Materials and Design. Elsevier Ltd, vol. 46, pp. 142-150.

Díaz, A, Katsarava, R \& Puiggalí, J 2014, 'Synthesis, properties and applications of biodegradable polymers derived from diols and dicarboxylic Acids: From Polyesters to poly(ester amide)s', International Journal of Molecular Sciences, vol. 15, no. 5, pp. 7064-7123.

Guo, B. et al. 2004, 'Thermoplastic elastomers derived from scrap rubber powder/LLDPE blend with LLDPE-graft-(epoxidized natural rubber) dual compatibilizer', Macromolecular Materials and Engineering, vol. 289 , no. 4 , pp. 360-367.

Gurunathan, T, Mohanty, S \& Nayak, SK 2015, 'A review of the recent developments in 
biocomposites based on natural fibres and their application perspectives', Composites Part A: Applied Science and Manufacturing. Elsevier Ltd, vol. 77, pp. 1-25.

Imbernon, L \& Norvez, S 2016, 'From landfilling to vitrimer chemistry in rubber life cycle', European Polymer Journal, Elsevier Ltd, vol. 82, pp. 347-376.

Ismail, H \& Nordin, RNA 2002, 'The comparison properties of recycle rubber powder, carbon black, and calcium carbonate filled natural rubber compounds', PolymerPlastics Technology and Engineering, vol. 41, no. 5, pp. 847-867.

Khimi, SR \& Pickering, KL 2015 , 'Comparison of dynamic properties of magnetorheological elastomers with existing antivibration rubbers', Composites Part B: Engineering, Elsevier Ltd, vol. 83, pp. 175-183.

Kochthongrasamee, T, Prasassarakich, P \& Kiatkamjornwong, S 2006, 'Effects of redox initiator on graft copolymerization of methyl methacrylate onto natural rubber', Journal of Applied Polymer Science, vol. 101, no. 4, pp. 2587-2601.

Mammadov, MS et al. 2012, 'Study of the structure and parameters of grid of hydrogenated butadiene nitrile rubber crosslinked with polymer peroxides', American Journal of Polymer Science, vol. 2 , no. 5, pp. 122-128.

Mas Haris, RHM \& Raju, G 2014 , 'Preparation and characterization of biopolymers comprising chitosan-graftedENR via acid-induced reaction of ENR 50 with chitosan', Express Polymer Letters, vol. 8, no. 2, pp. 85-94.

Mitragotri, S and Lahann, J 2009, 'Physical approaches to biomaterial design', Nature Materials, vol. 8, no. 1, pp. 15-23.
Notario, B, Pinto, J \& Rodriguez-Perez, MA 2016 'Nanoporous polymeric materials: A new class of materials with enhanced properties', Progress in Materials Science, Elsevier Ltd, vol. 78-79, pp. 93-139.

Pal, KV \& Panwar, JB 2017, 'Rubber blend nanocomposites', in Progress in Rubber Nanocomposites, 1st edn, eds S Thomas \& H. J. Maria, Woodhead Publishing.

Phinyocheep, P 2014, 'Chemical modification of natural rubber (NR) for improved performance', in Chemistry, Manufacture and Applications of Natural Rubber, Woodhead publishing, pp. 68-118.

Park, CY 2001, 'Cure characteristics and dynamic mechanical properties of acrylic rubber and epoxidized natural rubber blend', Journal of Industrial and Engineering Chemistry, vol. 7, no. 4, pp. 212-217.

Pedernera, M \& Sarmoria, C 1999, “An improved kinetic model for the peroxide initiated modification of polyethylene', Polymer Engineering, vol. 39, no. 10, pp. 2085-2095.

Piya-Areetham, P, Rempel, GL \& Prasassarakich, P 2014, 'Hydrogenated nanosized polyisoprene as a thermal and ozone stabilizer for natural rubber blends', Polymer Degradation and Stability, Elsevier Ltd, vol. 102, no. 1, pp. 112-121.

Rajasekar, R. et al. 2009, 'Development of nitrile butadiene rubber-nanoclay composites with epoxidized natural rubber as compatibilizer', Materials and Design, vol. 30, no. 9, pp. 3839-3845.

Ramesh, M 2016, 'Kenaf(Hibiscus cannabinus L.) fibre based bio-materials: A review on processing and properties', Progress in Materials Science, Elsevier Ltd, vol. 78-79, pp. 1-92. 
Sin, M. C. et al. 2014, "Viscoelastic, spectroscopic, and microscopic characterization of novel bio-based plasticized poly(vinyl chloride) compound', International Journal of Polymer Science, 2014, pp. 1-10.

Thitithammawong, A, Nakason, C, Sahakaro, K \& Noordermeer, JWM 2007, 'NR/PP thermoplastic vulcanizates: Selection of optimal peroxide type and concentration in relation to mixing conditions', Journal of Applied Polymer Science, vol. 106, no. 4, pp. 2204-2209.

Thitithammawong, A, Nakason, C, Sahakaro, K \& Noordermeer, JWM 2007, 'Thermoplastic vulcanizates based on epoxidized natural rubber/polypropylene blends: Selection of optimal peroxide type and concentration in relation to mixing conditions', European Polymer Journal, vol. 43, pp. 4008-4018.

Ulbricht, M 2006, 'Advanced functional polymer membranes', Polymer, vol. 47, no. 7, pp. 2217-2262.
Varghese, S, Karger-Kocsis, J \& Gatos, KG 2003, 'Melt compounded epoxidized natural rubber/layered silicate nanocomposites: structure-properties relationships', Polymer, vol. 44, no. 14, pp. 3977-3983.

Vinod, VS, Varghese, S \& Kuriakose, B 2002, 'Degradation behaviour of natural rubberaluminium powder composites: effect of heat, ozone and high energy radiation', Polymer Degradation and Stability, vol. 75, no. 3, pp. 405-412.

Wan Yunus, WMDZ. et al. 2013, 'Preparation and characterisation of crosslinked polycaprolactone and natural rubber (SMR CV 60) blends', Journal of Rubber Research, vol. 16 , no. 3 , pp. 147-161.

Wang, R. et al. 2016, 'Design, preparation and properties of bio-based elastomer composites aiming at engineering applications', Composites Science and Technology, Elsevier Ltd, vol. 133, pp. 136-156. 